\title{
Analysis on Chinese Network Literature Going-out
}

\author{
Jingping Yang \\ College of Humanities and Social Sciences, Heilongjiang Bayi Agricultural \\ University, Daqing, 163319, China \\ wendy5432@163.com
}

\begin{abstract}
At present, the external dissemination of network literature in China is in a process of promotion from the bottom up, from the outside to the inside. The folk translation force abroad is the main force of China's network literature dissemination, which has formed a certain scale and influence. But those who are responsible for the article translation are mostly spontaneous forces and the translation level is uneven, many translators lack the knowledge of the Chinese culture background, some translations of the original Chinese cultural elements involved in lots of translation errors and are easy to produce misunderstanding. Based on the analysis of 25 articles during 2014 to 2018 from CNKI database in China by using CiteSpace 5.6.R2, this paper tries to focus on the main aspects in these researches, to see which aspect they have focused on and analyze the successful reasons of Chinese literature going-out and at the same time to point out some aspects that people should pay attention to during the process of Chinese network literature going out.
\end{abstract}

KEYWORDS: network literature, going-out, CiteSpace, translation

\section{Introduction}

Network literature has gradually become an important part of China's cultural soft power. At the end of 2016, qidian.com and Wuxiaworld announced their cooperation, signed a ten-year cooperation agreement on translation and electronic publishing, and initially reached a cooperation agreement on 20 works, exploring a new mode of China's network literature export. Xiaodong Wang, Secretary General of the Shanghai Municipal People's Congress, vice-chairman of Shanghai Committee thinks that the output of our network literature in Europe and America mainly focuses on Chinese traditional mystery novels which has evolved a new system of the fantasy, cultivate immortality and aerial history for most foreign language translation of fictions. 


\section{Definition of Chinese Network Literature}

It has been 25 years since the mainland of China was connected to the Internet in 1994, and the development of network literature has reached its 24th year in 2018. Network literature refers to the super long popular novels published online and serialized on the Internet, which are completed on the Internet from the creation and release of authors to the reading and comments of readers.

In the past 20 years, China has produced 24.22 million works of network literature, and the number of writers based in major network literature enterprises has reached 17.55 million. According to the statistical survey of Internet development in China, by June 2018, the number of Internet literature users in China had reached 455 million, accounting for $52.1 \%$ of the total number of Internet users in China (CNNIC, 2018).

At present, there are many researches on network literature in China. Youquan Ouyang, a domestic scholar who made deeper research on the network literature, defined network literature as "published by Internet users on a computer creation, through the Internet, for Internet users to enjoy or participate in the new literary style, it is accompanied by the development of modern computer especially the digitized network technology of a new literary form" in the book "Introduction to Network Literature" (2008). He also mentioned that there was a great difference between network literature and traditional literature. Network literature is a 'new folk literature' in which literature returns to the public, which was "free" because it was embodied in the network virtual space and contained "the cultural logic of postmodernism”.

\section{Research on Chinese Network Literature}

\subsection{The Research on Network Literature in China and Abroad}

Some scholars believe that Chinese online novels are not only cosmopolitan (Yangquan Li, 2018), but also have distinct national characteristics and contain rich elements of Chinese classical culture. Baiyi Zhou (2013) believes that one of the sources of characters and clues in network literature is Chinese history, mythology and classical novels. In short, there are still many spaces for scholars to explore in the field of domestic network literature. At present, the research perspective of the academic circle is still relatively narrow, mostly focusing on the field of literature, lacking of "interdisciplinary and interdisciplinary” research (Baozhi Chen, 2018).

Compared with China, there are few researches on network literature abroad, and the research focus is different from those in China. This is mainly due to the great difference between China and foreign countries, especially in Europe and America. For the definition of network literature, foreign scholars mainly focus on the technical level (Koskimaa, 2010; Hayles, 2008; Gendolla\&Schafer, 2010), they seldom launch the research on network literature from the perspective of literature activity and industry; Some scholars point out that "network literature”, a relatively 
fixed concept, has not appeared in European and American countries like China, and the definition of "network literature" has not been unified in academic circles (Baiyi Zhou and Shanshan Lu, 2018). Moreover, in foreign countries, the research field of "electronic literature" is mainly focused on the hypertext of the carrier of the literature, which is mainly involved in cognitive and computer science field (Jianwei Zheng, 2018).

\subsection{The Developing History of Chinese Network Literature}

The development of Chinese network literature can be divided into four stages:

The first stage is from 1991 to 1998, under the condition of the domestic Internet environment were not popular, Chinese student abroad in search of traditional to China culture emotional sustenance founded the first online Chinese Huaxia's Digest Magazine, the prototype of the network literature has formed, then "olive tree" and "new threads" and so on network literature publication gradually rise, the stage become the infancy of network literature.

The second stage was from 1998 to 2004, marked by the popularity of "The First Intimate Contact" and the emergence of "Under the Banyan Tree" and other online literature sites, which became the development stage of network literature. At this stage, the Internet was gradually popularized, and network literature sites appeared one after another. However, only a few works were created by netizens, which could not be called a network literature creation platform in a real sense. "Network literature" became a popular word at that time.

The third stage was from 2004 to 2013, characterized by the rise of online charging reading modes such as read-write-web and qidian.com, and the commercialization of online literature began. “Qidian Chinese network” originated from the association of Xuanxuan literature established by the fans of network Xuanxuan literature, which occupies an important position in the development history of network literature.

The fourth stage is from 2014 to 2018. The emergence of multi-profit model represented by Shanda literature means that online literature has entered the stage of full commercialization. In order to ensure the continuity of a series of profit models, domestic commercial literature websites pay more attention to the mutual promotion of online literature content and website platform, so as to improve the attraction of authors and readers. It only takes a short period of more than ten years from the bud to the original growth of the development of network literature.

Network literature is a new form of Chinese literature. Throughout the development of Chinese literature, it has experienced three stages: ancient literature, modern and contemporary literature and network literature. The ancient literature contains the ancient wisdom of China. The modern and contemporary literature has enlightened the Chinese people's cognition of the imperial system and found that freedom and democracy are the living conditions of human beings, while the online literature has thoroughly implemented such freedom and democracy. 
With the implementation of China’s “One Belt And One Road” national strategy, China's network literature has risen to prominence in Southeast Asia and northeast Asia, selling well in many countries and regions in Asia and North America. It has become a new situation and new approach to promote Chinese network literature to go out and expand the international influence of Chinese culture (Xiao Liu, 2017).

\section{The Current Research Situation of Chinese Literature Going-out Based on CiteSpace Analysis}

\subsection{Method and the Source of the Data}

By using CiteSpace5.6.R2, this 3.paper gathered the data from CNKI (China National Knowledge Infrastructure) and made the analysis on the development of Chinese network literature from 2000 to 2018. By Jan 28, 2018, there are 803 papers were obtained by searching the topic "Chinese network literature" in CNKI, but when searching "Chinese network literature going out/ going global”, there are only 25 papers retrieved. This paper will only focus on the 25 researches relating to "Chinese network literature going out/ going global”. Due to the small number of articles published at home and abroad from 2000 to 2014, this paper used articles published from 2014 to 2018 as the original data for the atlas analysis of Chinese network literature research.

\subsection{The Current Situation of Chinese Network Literature Going-out}

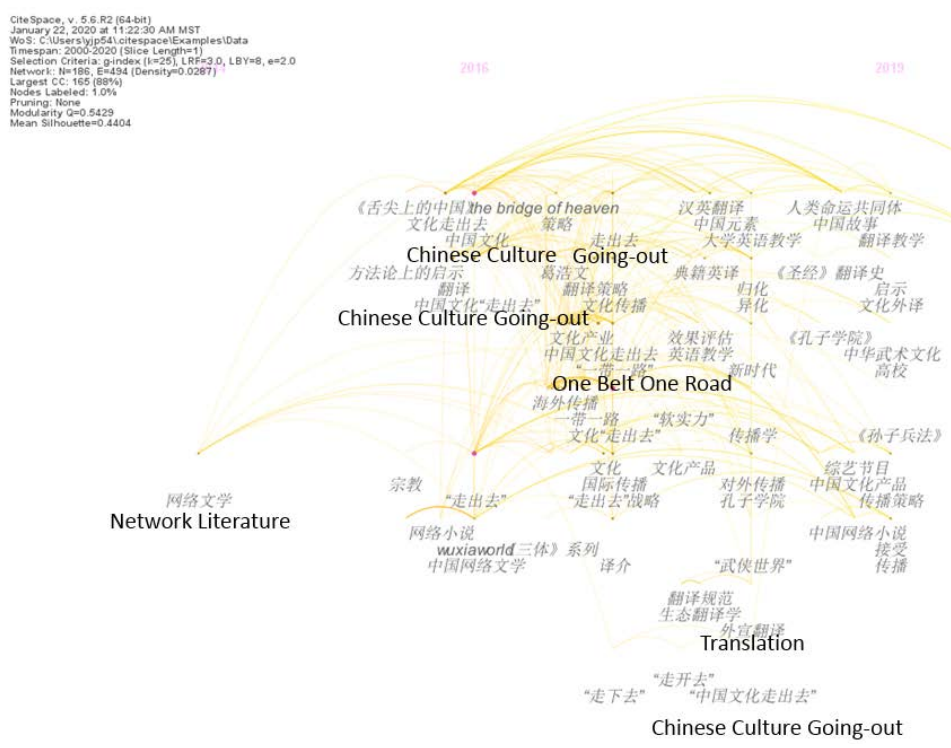

Figure. 1 Timeline Analysis of Chinese Network Literature in CNKI 


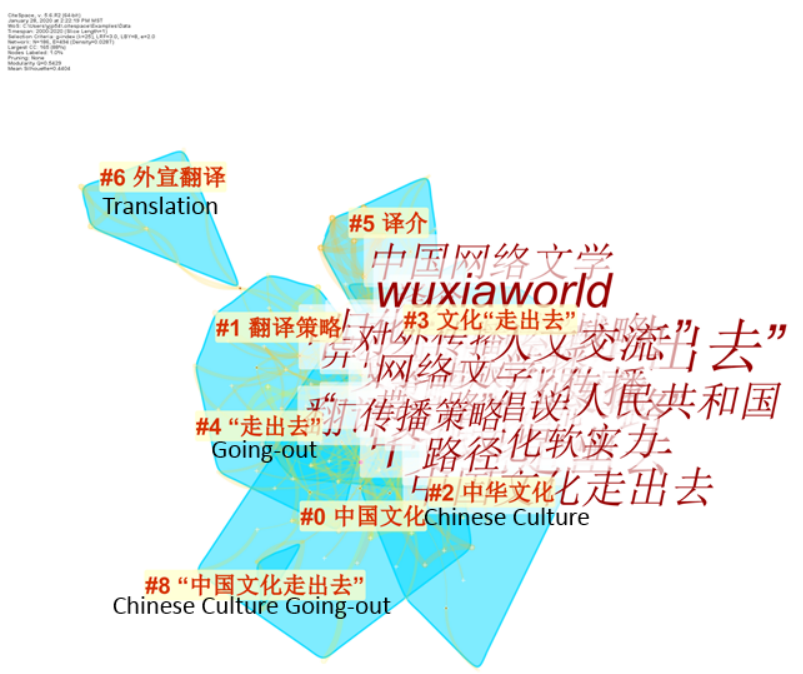

Figure. 2 Cluster View of Chinese Network Literature in CNKI

From the above pictures, we can clearly know the development of Chinese network going out. Directly searching words "Chinese network going-out" in the CNKI database, the researches on Chinese network literature by timeline will be shown in the picture above. We can see that all the researches are focused from 2014 to 2018, which means that the cluster is just within this time period. People began to pay much more attention to the Chinese network literature going-out, which falls in the 4th stage of the network literature.

In January 2015, the State General Administration of Press and Publication, Radio and Television issued by the "About Promoting the Guidance to the Healthy Development of the Network Literature", clearly put forward "conducting external exchanges, promote the going-out, encourage active network literature entering the international market”, in the form of official documents, external communication on network literature should give policy support. The Guidance On Further Strengthening and Improving the Chinese Culture to Go out (2016) , The Ministry of Culture in Culture Development Action Plan stressed area strategy as the future of our country's main window, intercultural communication should promote the countries along the area and the cultural exchanges of our country. We can clearly see that with Chinese culture going out strategy, lots of researches focused on Chinese culture, translation combined with Chinese network literature began to emerge.

There is one important reason for the researches blooming since 2017 as shown in Picture 1. In May 2017, China hosted the “One Belt And One Road” international summit forum. At the same time, the "One Belt And One Road” China network literature forum, sponsored by the online literature committee of the China writers 
association and the publicity department of the CPC municipal committee, opened in Lanzhou (Chao Li, 2017). The opening of the forum indicates that the strategy of "One Belt And One Road" will become an important background and channel in the practice of international communication of network literature in China, and the countries and regions along "One Belt And One Road" will become the main window of international communication of network literature in the future. At the same time, the promulgation of the policy also marks that the national support to enhance the external dissemination of network literature has been put on the agenda.

An important form of Chinese culture going-out is the translation and introduction of Chinese literature. Over the past decades, China has been promoting the going-out of Chinese culture by launching a number of translation projects. In terms of traditional culture, China has carefully selected and translated many classic works containing the essence of Chinese traditional culture, which have been published overseas, but they have not received much attention. For example, the great China library, a project to translate classical books, contains such classics as Mengxi Bitan and Sun Tzu's Art of War. The contents of the library are described so elaborate, but there are few readers and comments (Weirong Li, 2016).

In terms of the translation of modern and contemporary literature, although China has made some achievements, such as Mo Yan, Mai Jia, Su Tong, Yu Hua and other writers whose works have been published overseas and received favorable reviews, the overall "output" is far less than the "input". Translation field in our country long-standing trade deficit with China, literature, publications import \& export proportion is about 10:1, in the face of the United States, Britain, Germany, France, Canada and other major European and American countries of deficit of more than100:1 (Xiaocheng Zhu, 2018). In recent years, our country introduced 150 kinds of books from the United States, but the United States introduced fewer than 10 species of the Chinese book (BaoXiaoYing, 2015).

The cross-cultural communication effect of Chinese literature going-out is not ideal (Wang Caiying \& Hou Guojin, 2018), but online novels have risen to popularity among overseas readers. Since 2014, Chinese online novels have been translated into English spontaneously by overseas translators, triggering a "Chinese network novel craze" abroad. Readers from four sides of overseas translation websites wait for the translators to update the translation of the novel every day, and have a lively exchange on the plot of the novel and the Chinese cultural elements contained in it, such as "Tao", "Yin and Yang” and "qi”" (China News, 2016; CNR.cn, 2017; CCTV.com, 2017). China’s overseas network novel acceptance effect is good, reading widely overseas, some scholars to data statistics and questionnaire survey, the results show that there are more than 51 organizations specially focusing on Chinese network literature translation, the number of translations is at least 364 units, and the translation teams are more than 122, "compared with the traditional small-scale translated literature abroad, the current China's overseas network novel translation activities are more active. 


\section{The Reasons of the Success Going-out of Chinese Network Literature}

For a long time, due to the differences between China's social system and ideology and the western world, China's propaganda and methods are not scientific enough in terms of cultural exchanges, which makes it difficult for Chinese publications to enter foreign markets and restricts the dissemination function of publishing. (Xuehai Zhang, 2012:94) Chinese literature is "kept in deep boudoir and unknown”.

The fastest development results of Chinese network literature are from the social impact of the Chinese traditional literature and reform and opening up policy of China. Network literature is not a celestial being, but based on the deep soil of Chinese literary tradition. Chinese civilization is the only form of civilization that originated earlier in the world and continues to this day. Among the four major civilizations of ancient Greece, ancient Egypt, ancient Babylon and ancient China, only the Chinese civilization continues to make contributions to the world civilization with a new attitude. Among them, Chinese literary tradition is indispensable.

In 1978, China started the reform and opening up. Forty years later, China has made great achievements in all aspects, laying the material foundation for the development of Chinese literature, especially the Internet literature, which is highly technical.

Firstly, the living standards of the Chinese people have greatly improved. "Courtesy is known when granaries are full, and honor and disgrace are known when food and clothing are sufficient." At the beginning of the reform and opening up, China's per capita GDP was less than 400 yuan, equivalent to 149 dollars at that time. In 2018, four decades after reform and opening up, China's per capita GDP was about 9,777 dollars, a 25-fold increase. (http://www.zhicheng.com/gncj/n/ 243739.html) When the Chinese meet their material needs, they will naturally lead to a higher spiritual life. In addition, China's huge population has formed a network literature phenomenon with Chinese characteristics.

Secondly, China's international status has improved significantly, creating a favorable external environment. China's sustained and steady economic growth has not only improved the lives of its people, but also set an example for the rest of the world. More and more people are learning Chinese, and more and more foreign students are studying in China. After China is integrated into the WTO system, its influence on the outside world is also growing. China is connected to the world Internet and interconnects with the rest of the world, which creates good external conditions for the internationalization of online literature.

Thirdly, China has made rapid progress in science and technology. China's reform and opening up not only introduced many advanced technologies and management methods, but also made many important scientific and technological innovations with independent intellectual property rights. Mozi Scientific Laboratory, high-speed network extending in all directions, the face recognition technology has reached the international advanced level, a new generation of ten 
billion supercomputer Tianhe 3, first flight of big Chinese C919 aircraft prototype etc., these new achievements for the development of network literature not only provides a vivid material, also provides important technical support.

Finally, the improvement of life and technological progress have updated Chinese people's concept. Nowadays, it has become a common understanding of the Chinese people to rejuvenate the country through science and technology. The practice of creative communities and creative cities has been carried out in various places. China's education reform and continuing education system are complete and universal, and lifelong learning is deeply rooted in the hearts of the people. Innovation, creativity and entrepreneurship have greatly stimulated the subjective initiative of the Chinese people, and great intellectual potential is surging up.

\section{Conclusion}

Chinese network literature did achieve some success in going out recently. However, there are still some problems in Chinese network literature going out, such as lack of the professional translators who are familiar with the translation of Chinese culture which is the important factor responsible for restricting the goingout of Chinese network literature. These network literature translations are normally made by the volunteer translators, with different levels of the translation, or some may lack the knowledge of the Chinese culture background, or some translations of the original articles are easy to produce misunderstanding because of the inappropriate translation of the Chinese cultural elements involved in the translation, so if we want to seize the opportunity for the Chinese network literature going-out and let them be popular in the west, it is a new journey for us at present in our country in the development of the network literature to explore the new model of the network literature translation to spread to the west.

But facing the cultural differences between countries, Xiaoman Zhang (2017) also pointed out that we must actively improve the translation quality of our network literature in the propagation process and enhance China's cultural interpretation on the country's international force, to deepen the understanding towards Chinese culture and the whole country all the way along “One Belt and One Road” countries, so as to help advance of this going-out strategy. She also suggests that it is necessary to strengthen the construction of talents related to the international communication of Chinese network literature, cultivate excellent translators, train foreign language talents with deep knowledge of Chinese culture in colleges and universities, promote exchanges and cooperation with overseas universities and training institutions, cultivate talents with international vision, and help Chinese network literature to speed up the pace of going-out of network literature in China.

\section{Acknowledgments}

This research was financially supported by the Ecological Research of Western Network Literature from the Perspective of New Media (Project No. 14D046) and a 
study on the Reform of English Curriculum for Non-english Majors in Agricultural Colleges and Universities (JGXM_HLJ2014100).

\section{References}

[1] http://www.sohu.com/a/348704000_412025

[2] Rui Wang, Analysis of the English Translation and Dissemination of Chinese Online Novels from the Perspective of Media-translatology, Master thesis, 2018

[3] Youquan Ouyang, Introduction to Network Literature, 2008

[4] Rasuleva Nigina, (2018) The Research on the Development of Chinese Network Literature, Doctoral Dissertation 